\title{
Comportamento de abelhas visitantes florais de Lecythis lurida (Lecythidaceae) no norte do estado do Rio de Janeiro
}

\author{
Willian Moura Aguiar ${ }^{1} \&$ Maria Cristina Gaglianone ${ }^{1}$
}

${ }^{1}$ Laboratório de Ciências Ambientais, Universidade Estadual do Norte Fluminense Darcy Ribeiro, Av. Alberto Lamego, 2000, 28013-602,

Campos dos Goytacazes-RJ, Brasil.wmag26@yahoo.com.br; mcrisgag@uenf.br

\begin{abstract}
Behavior of flower visiting bees of Lecythis lurida in the north of Rio de Janeiro state. This study describes and analyses the behavior of $L$. lurida flower visitors in fragments of tabuleiro lowland forest. This monoecious species flowered from October to January. The flowers opened between 5:30 and 10:00 a.m. and floral anthesis did not exceed one day. Standardizing samples on flowers resulted in 172 bees, belonging to ten genera and 18 species. Epicharis flava (42,3\%), Xylocopa frontalis (16,3\%) and Eufriesea surinamensis (11,6\%) performed the highest relative frequencies, mainly occuring between 7:00 and 11:00a.m. Centridini, Euglossina and Xylocopini bees took nectar on flowers and were considered effective pollinators. Megachile collected pollen and also was potential pollinator. Oxaea flavescens acted as nectar thief by piercing the flower hood. Experiments of spontaneous autopollination indicated no fruit set and low fruit set $(0,48 \%)$ was observed in flowers under natural conditions. As discussed for other zygomorphic flowers of Lecythidaceae, the complex floral morphology restrict visitors to large or robust bees that can get into the flower through the floral hood. Nevertheless Centridini was the main pollinator group of L. lurida, which differs from the pollinators indicated in other studies on Lecythidaceae in the Amazonian region.
\end{abstract}

KEYWORDS. Atlantic Forest; Inhaíba; melitophily; pollination; solitary bees.

RESUMO. Comportamento de abelhas visitantes florais de Lecythis lurida no norte do estado do Rio de Janeiro. Este estudo descreve e analisa o comportamento dos visitantes florais de L. lurida em fragmentos de mata de tabuleiro. Esta espécie monóica floresceu de outubro a janeiro. As flores abriram-se entre $5 \mathrm{~h} 30$ e $10 \mathrm{~h} 00$ e a antese floral não ultrapassou um dia. Durante amostragens padronizadas foram coletadas 172 abelhas visitantes florais, pertencentes a 10 gêneros e 18 espécies. As maiores freqüências foram de Epicharis flava (42,3\%), Xylocopa frontalis (16,3\%) e Eufriesea surinamensis $(11,6 \%)$, com atividade principalmente de 7 h00 às $11 \mathrm{~h} 00$. Abelhas Centridini, Euglossina e Xylocopini buscam néctar nas flores e foram considerados polinizadores efetivos. Megachile coleta pólen e também é potencial polinizador. Oxaea flavescens atuou como pilhador de néctar, perfurando o capuz da flor. Experimentos de polinização indicaram ausência de autopolinização espontânea e baixa taxa de frutificação $(0,48 \%)$ sob condições naturais. Como observado para outras espécies zigomórficas de Lecythidaceae, a complexa morfologia floral restringe os visitantes a abelhas de grande porte ou abelhas robustas que conseguem entrar pelo capuz floral. Entretanto, Centridini foi principal grupo de polinizadores de L.lurida, o que difere dos polinizadores indicados em outros trabalhos sobre Lecythis e outros gêneros de Lecythidaceae na região amazônica.

PALAVRAS-CHAVE. Abelhas solitárias; Inhaiba; Mata Atlântica; melitofilia; polinização.

A família Lecythidaceae possui distribuição pantropical, com 440 espécies descritas em 20 gêneros (Morton et al. 1997), sendo que cerca de 200 espécies da subfamília Lecythidoideae têm distribuição exclusivamente neotropical e formam possivelmente um táxon monofilético (Prance \& Mori 2004; Mori et al. 2007). No Brasil, espécies desta subfamília apresentam grande representatividade na floresta amazônica, tanto em riqueza de espécies quanto em abundância (Mori et al. 2001). Embora com menor número de espécies, a floresta atlântica costeira constitui outro ecossistema importante de distribuição desta subfamília (Mori 1995).

A distribuição disjunta nas florestas amazônica e atlântica de espécies do gênero Lecythis (Lecythidoideae), conhecidas como sapucaias, foi descrita por Mori \& Prance (1981), que atribuíram esta distribuição atual a processos geológicos e climáticos passados que teriam separado espécies ancestrais. Os autores discutem ainda que a dispersão não teria sido um fator importante nesta disjunção, justificando pelas características dos frutos, não apropriados para dispersão a longas distâncias.

Estudos detalhados sobre a biologia reprodutiva e polinização das espécies amazônicas estão disponíveis para diversos gêneros, como Eschweilera, Lecythis, Couroupita, Cariniana e Bertholletia (Prance 1976; Mori et al. 1978; Mori et al. 1980; Ormond et al. 1981; Mori \& Boeke 1987; LepschCunha \& Mori 1999; Maués 2002). Por outro lado, as espécies com distribuição na floresta atlântica foram menos estudadas (Mori 1995). Assim a existência do padrão disjunto de distribuição para espécies de Lecythidoideae representa uma oportunidade para comparações de polinizadores nestes dois ecossistemas.

As flores de Lecythidaceae são hermafroditas e apresentam profundas variações morfológicas no androceu relacionadas a diferentes sistemas de polinização. Dentre as espécies 
neotropicais a melitofilia foi descrita para a maioria das espécies que tiveram sua polinização estudada (Mori \& Boeke 1987; Lepsch-Cunha \& Mori 1999; Maués 2002). De maneira geral, flores cujo androceu é menos complexo, apresentam-se disponíveis para muitos grupos de polinizadores, enquanto flores morfologicamente complexas, devido a modificações do androceu, restringem a visitação a um menor grupo de polinizadores efetivos (Prance 1976; Mori \& Prance 1981; Mori \& Boeke 1987). A simetria floral e os recursos oferecidos a polinizadores também foram modificados ao longo da evolução floral, sendo o néctar recurso restrito a algumas espécies zigomorfas com maior complexidade do androceu (Mori et al. 1978). Entre estas estão as do gênero Lecythis, cuja biologia floral foi estudada em detalhes para algumas espécies na Amazônia. Lecythis pisonis Cambess foi descrita por Mori et al. (1980) como uma espécie dependente de Xylocopa frontalis para a produção de frutos. Outras espécies também são polinizadas por abelhas de grande porte, como Bombus e Xylocopa (Mori et al. 1978; Mori \& Boeke 1987; Lepsch-Cunha \& Mori 1999; Maués 2002).

Lecythis lurida é uma espécie com registros na floresta amazônica e na floresta atlântica (Mori 1980; Mori 1995), conhecida popularmente como "jarana" na região amazônica (Mori 1981) e "sapucainha ou inhaíba" na região norte do Estado do Rio de Janeiro, onde sua ocorrência foi descrita nos remanescentes de mata sobre tabuleiro terciário (Silva \& Nascimento 2001). O estudo dos polinizadores de Lecythis lurida pode contribuir para o entendimento dos sistemas de polinização de espécies de distribuição disjunta, assim como ampliar o conhecimento das interações planta-polinizador nas matas de tabuleiro, um ecossistema de mata atlântica atualmente bastante ameaçado. Desta forma os objetivos deste estudo são descrever e analisar o comportamento dos visitantes florais de L. lurida, além de analisar alguns aspectos da biologia floral em fragmentos de mata de tabuleiro no norte do Estado do Rio de Janeiro.

\section{MATERIAL E MÉTODOS}

O estudo foi realizado em dois remanescentes de mata de tabuleiro (sensu Rizzini 1979), Mata do Carvão e Mata do Funil, em São Francisco do Itabapoana, RJ. A Mata do Carvão (21 $24^{\prime}$ S e $41^{\circ} 04^{\prime}$ W) faz parte da Estação Ecológica Estadual de Guaxindiba e é o mais significativo fragmento desta formação na região com 1.053 ha (Silva \& Nascimento 2001). A Mata do Funil ( $21^{\circ} 33^{\prime} \mathrm{S}$ e $\left.41^{\circ} 12^{\prime} \mathrm{W}\right)$ possui aproximadamente 135 ha e é floristicamente semelhante à Mata do Carvão (Nascimento, M.T. informação pessoal).

O clima na região, segundo a classificação de Köppen, é Aw, com temperaturas elevadas e chuva no verão e seca no inverno. As médias mensais de temperatura ao longo do ano são, em geral, maiores que $20^{\circ} \mathrm{C}$, sendo que no mês mais frio, julho, as mínimas são menores que $18^{\circ} \mathrm{C}$. A região apresenta precipitação média anual em torno de $1.000 \mathrm{~mm}$, com uma estação seca bem definida, de maio a setembro (RadamBrasil 1983). Porém, nos anos de 2004 e 2005, período do estudo, a precipitação registrada foi superior a 1.400mm (Fonte: Estação climatológica de Campos dos Goytacazes). O solo da região pertence à classe dos argissolos amarelo álico de alta granulometria, com baixa capacidade de retenção de água e pobre em nutrientes (Villela et al. 2006).

O estudo de visitantes florais de L. lurida foi conduzido em 14 indivíduos de porte arbóreo, com até $14 \mathrm{~m}$ de altura, sendo dez deles localizados na Mata do Carvão e quatro na Mata do Funil. Para verificar o período de floração foram realizadas inspeções quinzenais entre os meses de setembro de 2004 e março de 2005. Os dados relacionados a abelhas visitantes florais, incluindo freqüência de visitantes, análises de comportamento e experimentos de polinização foram realizados nos meses de novembro e dezembro de 2004. Durante o período de floração foram realizados oito dias de amostragens de visitantes florais e análise de comportamento, totalizando aproximadamente 64 horas de amostragens padronizadas, além de observações, coletas aleatórias e experimentos de polinização em outros 12 dias de amostragens.

Os visitantes florais foram coletados em plantas com intenso florescimento, em intervalos de 20 minutos a cada hora, de 6 h00 às 16 h00, com o auxílio de rede entomológica de cabo extensível. Um andaime de aproximadamente $8 \mathrm{~m}$ foi montado para coleta esporádica e observação do comportamento dos visitantes na copa das árvores. Foram analisados parâmetros de riqueza e diversidade de espécies, frequiência dos visitantes durante o dia, recurso coletado na flor e comportamento intrafloral. Testes para detecção de osmóforos foram realizados submergindo as flores por duas horas em solução de vermelho neutro $0,1 \%$ e posteriormente lavando-as em água corrente (Vogel 1978). Foram marcados 40 botões para verificar o período de antese, assim como a longevidade das flores. $\mathrm{O}$ diâmetro das flores foi determinado em 50 flores em antese, pela medida externa entre as pétalas. A concentração de açúcares no néctar floral foi verificada no campo com auxílio de refratômetro manual BS 45-03 com precisão de $0,5 \%$.

Para analisar a eficiência dos visitantes como polinizadores foram feitas análises de comportamento, medidas de tamanho corporal e presença de pólen no corpo. As análises de comportamento foram realizadas através de filmagens e fotografias com vídeo câmera digital e observação direta. O porte corporal dos visitantes, medido pela altura do tórax, foi tomado com auxílio de paquímetro ou sob estereomicroscópio com ocular milimetrada. A presença de pólen no corpo dos visitantes florais foi verificada através de análises em estereomicroscópio. Para confirmar se o pólen aderido era proveniente de L. lurida, foram confeccionadas lâminas em gelatina-fucsina glicerinada, conforme Dafni (1992). O pólen foi retirado da região dorsal do tórax, cabeça e asa, locais mais prováveis de contato com as estruturas reprodutivas. $\mathrm{O}$ pólen carregado nas escopas ou corbículas também foi analisado, a fim de verificar a coleta de pólen como recurso para o visitante. A porcentagem de grãos de pólen pertencentes a L.lurida no total de grãos de cada amostra foi determinada na contagem aleatória de 250 grãos de pólen em cada lâmina referente a uma 
abelha visitante. O número de abelhas examinadas variou entre uma e cinco conforme a freqüência da espécie visitante.

A porcentagem de frutificação foi verificada em experimentos de polinização em condições naturais, que consistiram da marcação de flores em inflorescências e o seu acompanhamento até a formação de frutos, e ensacamentos para verificação de autopolinização espontânea, em que todos os visitantes florais foram excluídos através do isolamento das inflorescências com sacos de voile. Cada experimento foi realizado em 50 inflorescências, totalizando 520 flores para polinização em condições naturais e 621 flores nos experimentos de autopolinização espontânea.

As abelhas capturadas foram depositadas no Laboratório de Ciências Ambientais (LCA/CBB) da Universidade Estadual do Norte Fluminense Darcy Ribeiro - UENF e a identificação foi realizada com base em comparação com a coleção de referência para a área estudada e consulta a especialistas.

\section{RESULTADOS}

Lecythis lurida é uma espécie monóica. As inflorescências são terminais, com 8 a $25 \mathrm{~cm}$ de comprimento $(\mathrm{n}=100$, média $=14 \mathrm{~cm}, \pm 4,49)$, e apresentaram de 4 a 22 botões $(n=50$, média $=15$ botões, $\pm 4,58)$. Uma ou no máximo duas flores se abriram por dia em cada inflorescência (Fig. 1). As flores começaram a abrir por volta de 5h30, e até às 10 h00 todas estavam completamente abertas sendo que nenhuma das flores marcadas ultrapassou um dia de longevidade.

As flores são bissexuadas, zigomorfas e vistosas, de coloração avermelhada na face externa e na borda interna das pétalas e cor amarelada na face interna das pétalas, no capuz e na lígula. $\mathrm{O}$ anel estaminal é composto por centenas de estames, a lígula é desprovida de estames e tem seu limite na base do capuz, onde se localizam estaminódios. As flores medem de 3 a $6 \mathrm{~cm}$ de diâmetro $(\mathrm{n}=50$, média $=4,75 \mathrm{~cm}, \pm 0,86)$, possuem seis pétalas e seis sépalas unidas na base. O teste com vermelho neutro revelou a presença de osmóforos na região do anel estaminal até a região mediana interna do capuz, na porção interna das pétalas e na base dos estaminódios localizados no capuz. O néctar foi localizado na região central do anel estaminal e na base da lígula (Fig. 1), sendo que a sua concentração não ultrapassou 2,5\% ( $n=30$ flores, média $=1,6 \pm 0,6 \%$ ).

L. lurida floresceu de outubro de 2004 a janeiro de 2005. Neste período foram amostradas nas coletas padronizadas 172 abelhas pertencentes a 10 gêneros e 18 espécies. Os visitantes florais mais freqüentes foram Epicharis flava (Friese, 1900), Xylocopa frontalis (Olivier, 1789) e Eufriesea surinamensis (Linnaeus, 1758) (Tabela I).

A maior freqüência de visitantes florais ocorreu entre $7 \mathrm{~h} 00$ e $11 \mathrm{~h} 00$, com um pico secundário entre $13 \mathrm{~h} 00$ e $14 \mathrm{~h} 00$. A partir das $14 \mathrm{~h} 00$ houve diminuição das visitas, que cessaram por volta de 16h00. Euglossina, Centridini e Xylocopini visitaram

Tabela I. Abelhas visitantes florais com suas respectivas abundâncias relativas, medidas corporais, porcentagem de pólen de Lecythis lurida aderido ao corpo e indicação de potenciais polinizadores. AT= altura do tórax $(\mathrm{cm}), \% \mathrm{PC}=$ porcentagem de pólen de L.lurida no corpo (tórax, cabeça e asas), (n)= número de indivíduos analisados, $\mathrm{SP}=$ espécies sem pólen aderido ao corpo, $\mathrm{P}=$ potencial polinizador, $\mathrm{Pi}=\mathrm{Pilhador}$, n.i.=não identificado.

\begin{tabular}{|c|c|c|c|c|c|c|}
\hline & Espécies & Sexo & Freq.Relativa $(\%)$ & AT(Média) & $\%$ PC (n) & Comportamento \\
\hline \multicolumn{7}{|l|}{ ANDRENIDAE } \\
\hline OXAEINAE & Oxaea flavescens Klug, 1807 & + $0^{x}$ & 4,1 & 0,54 & $\mathrm{SP}(5)$ & $\mathrm{Pi}$ \\
\hline \multicolumn{7}{|l|}{ APIDAE } \\
\hline \multirow[t]{5}{*}{ CENTRIDINI } & Centris decipiens Moure \& Seabra, 1960 & $\sigma^{\top}$ & 0,6 & 1,0 & $\mathrm{SP}(1)$ & $\mathrm{P}$ \\
\hline & Centris flavifrons (Fabricius, 1775) & q & 0,6 & 0,80 & $58(1)$ & $\mathrm{P}$ \\
\hline & Centris aff. longimana Fabricius, 1804 & $\sigma^{x}$ & 2,3 & 0,81 & $18-90(3)$ & $\mathrm{P}$ \\
\hline & Epicharis fasciata Lepeletier \& Serville, 1828 & 웅 & 2,3 & 0,69 & $30-75(2)$ & $\mathrm{P}$ \\
\hline & Epicharis flava (Friese, 1900) & 웅 & 42,3 & 0,79 & $47-98(5)$ & $\mathrm{P}$ \\
\hline \multicolumn{7}{|l|}{ XYLOCOPINI } \\
\hline & Xylocopa frontalis (Olivier, 1789) & 우 & 16,3 & 1,08 & $97-100(5)$ & $\mathrm{P}$ \\
\hline & Xylocopa nigrocincta Smith, 1854 & 우 & 1,7 & 0,81 & $10-84(3)$ & $\mathrm{P}$ \\
\hline & Xylocopa ordinaria Smith, 1874 & 우 & 7,6 & 0,76 & $92-98(5)$ & $\mathrm{P}$ \\
\hline \multicolumn{7}{|l|}{ APINI } \\
\hline \multicolumn{7}{|l|}{ ALPINA } \\
\hline & Apis mellifera Linnaeus, 1758 & 우 & 2,3 & 0,42 & $\mathrm{SP}(2)$ & n.i. \\
\hline \multicolumn{7}{|l|}{ EUGLOSSINA } \\
\hline & Eufriesea surinamensis (Linnaeus, 1758) & + $0^{x}$ & 11,6 & 0,73 & $78-90(5)$ & $\mathrm{P}$ \\
\hline & Euglossa cordata (Linnaeus, 1758) & $\sigma^{x}$ & 0,6 & 0,43 & SP (1) & n.i. \\
\hline & Eulaema cingulata Fabricius, 1804 & $\sigma^{x}$ & 0,6 & 0,76 & $75,5(1)$ & $\mathrm{P}$ \\
\hline & Eulaema nigrita Lepeletier, 1841 & 웅 & 4,1 & 0,80 & $2-85(5)$ & $\mathrm{P}$ \\
\hline \multicolumn{7}{|l|}{ MELIPONINA } \\
\hline & Plebeia lucii Moure, 2004 & 우 & 0,6 & 0,09 & $\mathrm{SP}(1)$ & n.i. \\
\hline & Plebeia sp.1 & 우 & 0,6 & 0,14 & $\mathrm{SP}(1)$ & n.i. \\
\hline \multicolumn{7}{|c|}{ MEGACHILIDAE } \\
\hline & Megachile sp.1 & 우 & 1,2 & 0,42 & $90(1)$ & $\mathrm{P}$ \\
\hline & Megachile sp.2 & 우 & 0,6 & 0,44 & $98(1)$ & $\mathrm{P}$ \\
\hline
\end{tabular}




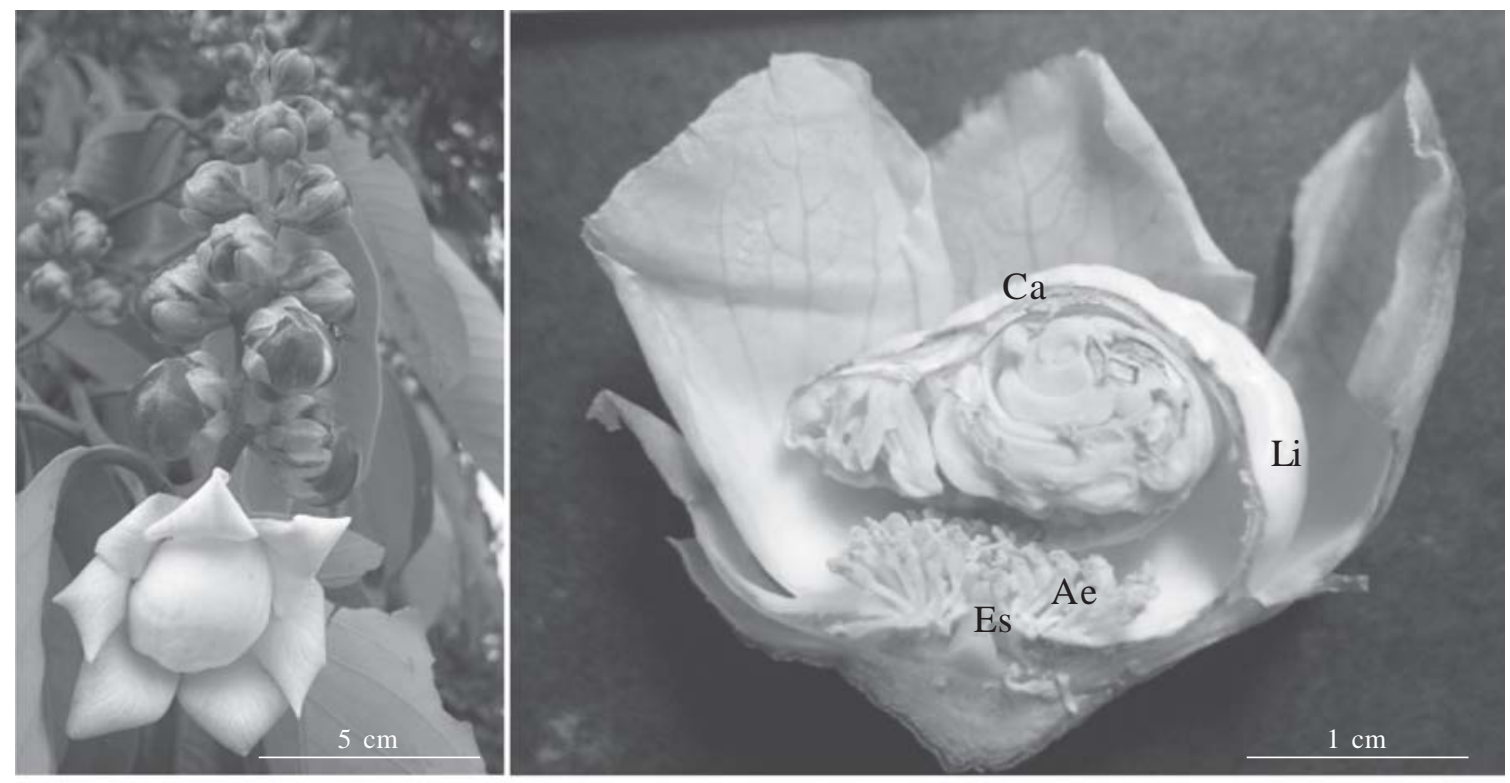

Fig. 1. Inflorescência de Lecythis lurida e flor em corte bilateral. Ca=capuz; Ae=anel estaminal; Es=estigma; Li=lígula

as flores durante todo o dia, e Oxaea flavescens visitou apenas no intervalo de 8 h00 às 9 h00 (Fig. 2).

As abelhas de grande porte dos gêneros Centris, Epicharis, Eulaema, Eufriesea e Xylocopa apresentaram comportamento semelhante. Sobrevoavam várias flores, pousando no capuz e dirigindo-se para a abertura existente entre o capuz e o anel estaminal, onde inseriam inicialmente a cabeça, em seguida o tórax, e às vezes, até o abdômen, sugerindo comportamento de coleta de néctar. Após a visita, sobrevoavam e visitavam outras flores no mesmo ou em outros indivíduos próximos.

Abelhas dos gêneros Epicharis e Xylocopa visitaram flores em antese e eventualmente botões. Essas abelhas forçavam as pétalas dos botões ainda túrgidos com a cabeça e as pernas anteriores para que se abrissem, de modo a facilitar sua entrada. As análises do material polínico de escopas e corbículas destas abelhas apresentaram, de maneira geral, menos de 5\% dos grãos de pólen pertencentes à $L$. lurida. X. frontalis, $E$. flava e $E$. surinamensis visitaram mais de 30 flores em seqüência na mesma planta ou em plantas coespecíficas próximas, onde foi possível a observação. Essas espécies permaneceram nas flores em média $27 \pm 19$ s, $28 \pm 13$ s e $25 \pm 17$ s, respectivamente.

Abelhas do gênero Megachile entravam com todo o corpo no interior da flor, saindo em seguida com a escopa abdominal carregada de pólen, indicando que este era o recurso procurado. Abelhas de grande e médio porte apresentaram quantidades consideráveis de grãos de pólen aderidos ao corpo, cabeça, tórax dorsal e asa. As análises polínicas demonstraram que o pólen aderido a estas regiões do corpo das abelhas era em sua maioria proveniente de flores de $L$. lurida, chegando a constituir até $100 \%$ do pólen no corpo de alguns indivíduos (Tabela I).

Apis mellifera, Plebeia lucii (Moure, 2004) e Plebeia sp.1 não conseguiam entrar na flor, e permaneciam por até alguns minutos rodeando o capuz da flor, aparentemente sem coletar qualquer recurso. Oxaea flavescens perfurava o capuz com as gáleas e inseria a probóscide na direção do anel estaminal, retirando néctar sem entrar na flor. Indivíduos dessas espécies não apresentaram pólen de L. lurida aderidos ao corpo. A visita de $O$. flavescens às flores podia também ser detectada pelas perfurações no capuz floral após a visitação.

Os experimentos de autopolinização espontânea não resultaram em frutificação. Já nos experimentos de polinização em condições naturais, observou-se a formação de frutos em $0,48 \%$ das flores testadas.

\section{DISCUSSÃO}

O período de florescimento de $L$. lurida coincide com o período chuvoso, aumento da temperatura e do fotoperíodo na região. Segundo Mori et al. (1980), o regime pluviométrico não pode ser considerado como fator primordial no controle de eventos fenológicos, mas o aumento do período de luminosidade e da temperatura que acompanham as estações de primavera e verão seriam determinantes no florescimento das espécies deste gênero.

O padrão de abertura diária de uma ou duas flores por dia em cada inflorescência de L. lurida é semelhante ao descrito para outras espécies dessa família. Como observado por Prance (1976), Mori \& Boeke (1987) e Maués (2002), este mecanismo de abertura floral faz com que os indivíduos desta família tenham seu período de floração prolongado por várias semanas, favorecendo a oferta de recursos aos visitantes florais.

A distribuição de osmóforos em flores de $L$. lurida indica a região central do anel estaminal e a base da lígula como locais de secreção de odores que atuam na atração de polinizadores, similar ao observado para outras espécies da família (Maués 2002). Embora a localização precisa dos nectários não tenha sido determinada, o acúmulo de néctar nesta região 
e o comportamento da maioria dos visitantes indicam que este é o recurso principal oferecido pelas flores de L. lurida. Estas observações são corroboradas pelas análises polínicas, que indicaram porcentagens muito pequenas de pólen desta planta nas corbículas e escopas das abelhas, com exceção de Megachile, que coleta pólen ativamente nestas flores.

As visitas de abelhas principalmente no período da manhã, logo após o início da antese, também foram observadas para outras espécies da família Lecythidaceae (Prance 1976; Maués 2002). A frequiência aproximadamente constante de abelhas Centridini e Euglossina entre 7 e 14h sugere que o néctar esteja disponível ao longo do dia. A concentração de açúcares verificada para $L$. lurida é muito menor do que a comumente observada entre as fontes utilizadas por abelhas (Roubik et al. 1995). Entretanto, segundo dados de Mori \& Boecke (1987), Lecythis persistens, apresentou valores de concentração de açúcares semelhantes, de 2-3\% no capuz e na base dos filamentos no anel estaminal. $\mathrm{O}$ uso de néctar diluído foi reportado para espécies de Euglossina de língua mais curta (Borrell 2003). Segundo Baker \& Baker (1983) a composição do néctar e as proporções dos diferentes açúcares, além da sua concentração total, podem estar envolvidas na seleção das fontes deste recurso pelos polinizadores.

Knudsen \& Mori (1996) e Mori \& Boecke (1987) citaram o pólen de alimentação como principal recurso para os polinizadores de algumas espécies de Lecythis. Para L. lurida o pólen de alimentação não foi caracterizado e grãos de pólen de diferentes regiões no anel estaminal não apresentaram variação morfológica, embora a sua viabilidade não tenha sido testada.

A morfologia complexa das flores de L. lurida restringe os visitantes que atuam como potenciais polinizadores às espécies de grande porte dos gêneros Centris, Epicharis, Eulaema, Eufriesea e Xylocopa, que preenchem todo o espaço existente entre o capuz e o anel estaminal durante suas visitas, e àquelas capazes de forçar a entrada pelo capuz, como Megachile. Observações semelhantes foram feitas por Mori et al. (1978), Müller et al. (1980) e Maués (2002), estudando outras espécies desta família.

A composição de espécies de abelhas visitantes de $L$. lurida difere da descrita por Mori et al. (1978) para outras espécies de Lecythidaceae com flores zigomórficas. Estes autores descreveram os principais polinizadores para vinte espécies de Lecythidaceae, dentre eles, os morcegos como polinizadores de Lecythis poiteaui Berg, algumas espécies de Polybia e de Trigona polinizadores de Couroupita subsessilis Pilg, abelhas de grande porte pertencentes à Euglossina como polinizadores de Bertholletia excelsa H.B.K., Eschweilera spp., Couratari spp. e as abelhas dos gêneros Xylocopa, Bombus, Trigona e Megachile como principais polinizadores de Lecythis spp. No presente trabalho, a maior frequiência de Centridini (48\% das visitas observadas) associada ao porte e comportamento destas abelhas os indica como principais polinizadores de L.lurida. Este resultado reflete a grande diversidade de espécies e abundância de Centridini observada nas matas de tabuleiro da região norte do estado do Rio de

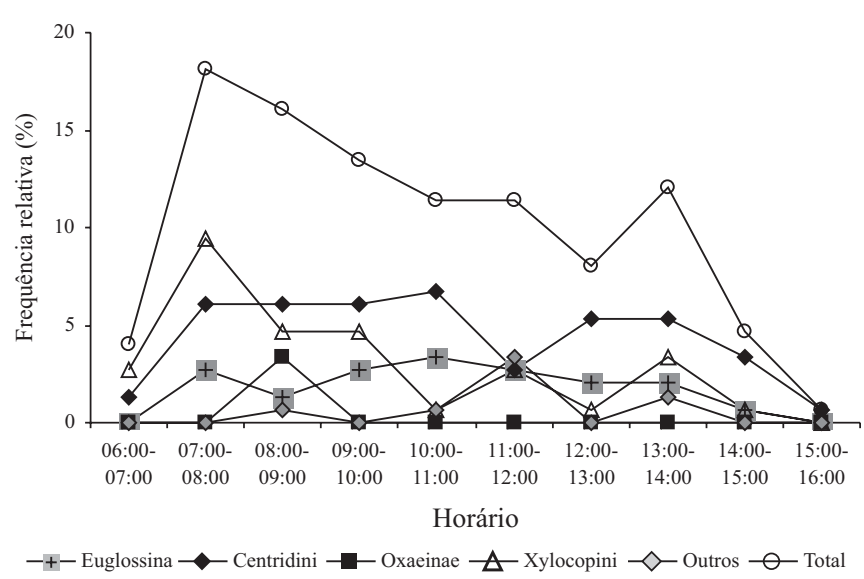

Fig. 2. Freqüência relativa de indivíduos e atividade ao longo do dia dos principais grupos de abelhas visitantes florais de Lecythis lurida na Mata do Carvão e Mata do Funil, São Francisco do Itabapoana, RJ.

Janeiro (Gaglianone 2006). Machos e fêmeas de Epicharis flava foram os principais polinizadores de L. lurida nas áreas estudadas. O comportamento polilético desta espécie, associado à atividade ao longo do ano, com várias gerações (Camargo et al.,1975), indica que não há especificidade às flores de Lecythidaceae. Entretanto, a grande freqüência de visitas em período de intenso florescimento de outras espécies na área (Gaglianone \& Menezes, dados não publicados) sugere que o néctar de L. lurida seja um recurso importante para esta espécie de abelha nas matas de tabuleiro.

Outros polinizadores importantes foram abelhas do gênero Xylocopa e Eufriesea surinamensis. Xylocopa frontalis e X. ordinaria são espécies generalistas, com atividade ao longo do ano, enquanto que $E$. surinamensis é sazonal, com atividade restrita ao período de novembro a janeiro, coincidente com o pico de floração de L. lurida. Abelhas do gênero Eufriesea já haviam sido indicadas como tipicamente sazonais (Dressler 1982).

O comportamento destas abelhas de grande porte caracteriza a polinização nototríbica, semelhante à descrita para potenciais polinizadores de outras espécies de Lecythidaceae que apresentam flores zigomórficas (Mori \& Boeke 1987; Maués 2002). De modo distinto, abelhas Megachile, também consideradas potenciais polinizadores de L. lurida, caracterizam-se pela polinização esternotríbica.

L. lurida necessita de polinização cruzada para formação de frutos, porém a taxa de frutificação verificada nas áreas estudadas foi baixa. Segundo Mori et al. (1980), a baixa frutificação em espécies de Lecythidaceae pode ser reflexo da pequena população de polinizadores. Já para Gamboa-Gaitán (1997), o alto custo energético para produção de frutos e sementes promove grandes níveis de aborto, tendo com isso baixa frutificação. No presente estudo, a baixa densidade populacional de polinizadores não parece ser o fator responsável pela baixa produção de frutos, visto que estudos na região demonstram altas densidades populacionais dos 
grupos de abelhas que são potenciais polinizadores de L.lurida (Gaglianone, M. C. dados não publicados). Porém, em observações aleatórias de campo pelo primeiro autor, pôde-se verificar intensa herbivoria das flores por coleópteros Rutelinae, o que pode ser um fator relevante para a baixa produção de frutos em L. lurida na região.

Agradecimentos. Probio-Polinizadores pelo suporte financeiro (Convênio MMA 0115-00/04), CNPq pela bolsa de apoio técnico (ATNS), João Marcelo A. Braga (Jardim Botânico-RJ) pela identificação taxonômica da espécie estudada, Gabriel A. R. Melo (UFPR) e João M. F. de Camargo (USP-RP) pela identificação das abelhas. Esta é uma contribuição do Programa de Pós-Graduação em Ecologia e Recursos Naturais-UENF.

\section{REFERÊNCIAS}

Backer, H. G. \& I. Backer. 1983. Floral nectar sugar constituents in relation to pollinator type, 117-141 p. In: C. E. Jones \& R. J. Little (eds) - Handbook of Experimental Pollination Biology. Van Nostrand Reinhold Company Inc.

Borrell, B. J. 2004. Suction feeding in orchid bees (Apidae: Euglossini). Proceedings of the Royal Society of London 271: 164-166.

Camargo, J. M. F.; R. Zucchi \& S. F. Sakagami. 1975. Observations on the bionomics of Epicharis (Epicharana) rustica flava (Olivier) including notes on its parasite, Rhathymus sp. (Hymenoptera, Apoidea: Anthophoridae). Studia Entomologica 18: 310-340.

Dafni, A. 1992. Pollination ecology: a practical approach. Oxford University. Press, $250 \mathrm{p}$.

Dressler, R. L. 1982. Biology of the orchid bees (Euglossini). Annual Review in Ecology and Systematics 13: 373-394.

Gaglianone, M. C. 2006. Centridini em Remanescentes de Mata Atlântica: Diversidade e Interações com Flores. Encontro sobre Abelhas 7: 335-340.

Gamboa-Gaitán, M. A. 1997. Biología reproductiva de Eschweilera bogotensis (Lecythidaceae), en la cordillera occidental de Colombia. Caldasia 19: 479-485.

Knudsen, J. T. \& S. A. Mori. 1996. Floral Scents and Pollination in Neotropical Lecythidaceae. Biotropica 28: 42-60.

Lepsch-Cunha, N. \& S. A. Mori. 1999. Reproductive phenology and mating potential in a low density tree population of Couratari multiflora ( Lecythidaceae) in central Amazonia. Journal of Tropical Ecology 15: 97-121.

Maués, M. M. 2002. Reprodutive phenology and pollination of the Brazil nut tree (Bertholletia excelsa Humb. \& Bonpl., Lecythidaceae) in Eastern Amazonia. In: P. Kevan \& V.L. Imperatriz Fonseca (eds) - Pollinating Bees - The Conservation Link Between Agriculture and Nature - Ministry of Environment / Brasilia. p. $245-254$.

Mori, S. A.; L. A. Mattos Silva \& T. S. dos Santos. 1980. Observações sobre a fenologia e biologia floral de Lecythis pisonis Cambess. (Lecythidaceae). Revista Theobroma 10: 103-111.

Mori, S. A. \& G. T. Prance. 1981. The "sapucaia" Group of Lecythis (Lecythidaceae). Brittonia 33: 70-80.

Mori, S. A. 1981. New species and combinations in Neotropical Lecythidaceae. Brittonia 33: 357-370.
Mori, S. A. 1995. Observações sobre as espécies de Lecythidaceae do leste do Brasil. Boletim de Botânica, Universidade de São Paulo 14: 1-31.

Mori, S. A.; P. Becker \& D. Kincaid. 2001. Lecythidaceae of a central Amazonian lowland forest. Implications for conservation. Pp. 5467. In: R. O. Bierregaard, Jr., C. Gascon, T. E. Lovejoy \& 16 R. C. G. Mesquita (eds.). Lessons from Amazonia. The ecology and conservation of a fragmented forest. Yale University Press, New Haven \& London.

Mori, S. A.; C. H. Tsou; C. C. Wu; B. Cronholm \& A. A. Anderberg. 2007. Evolution of Lecythidaceae with an Emphasis on the Circumscription of Neotropical Genera: Information from Combined Ndhf and Trnl-F Sequence Data. American Journal of Botany 94: 289-301.

Mori, S. A. \& J. D. Boeke. 1987. Pollination. Chapter 12 In: S. A. Mori \& Collaborators (eds). The Lecythidaceae of a lowland neotropical forest: La Fuméc Mountain, French Guiana. Memoirs of the New York Botanical Garden 44: 137-155.

Mori, S. A.; G. Prance. \& A. B. Bolten. 1978. Additional notes on the floral biology of neotropical Lecythidaceae. Brittonia 30: 113130 .

Mori, S. A.; L. A. M. Silva. \& T. S. Santos. 1980. Observações sobre fenologia e biologia floral de Lecythis pisonis Cambess. (Lecythidaceae). Revista Theobroma 10: 103-111.

Morton, C. M.; S. A. Mori; G. T. Prance; K. G. Karol \& M. W. Chase. 1997. Phylogenetic relationships of Lecythidaceae: A cladistic analysis using rbcL sequence and morphological data. American Journal of Botany 84: 530-540.

Müller, C. H.; I. A Rodrigues; A. A. Müller \& N. R. M. Müller. 1980. Castanha do Brasil: Resultado de pequisa. EMBRAPA/CPATU. Miscelância 2: 1-25

Ormond, W. T.; M. C. B. Pinheiro \& O. A. R. C. de Castells. 1981. A contribution to the floral biology and reproductive system of Couroupita guianensis Aubl. (Lecythidaceae). Annals of the Missouri Botanical Garden 68: 14-523.

Prance, G. T. \& S. A. Mori. 2004. Lecythidaceae. 221-232 p. In: K. Kutbitski (ed.). The Families and Genera of Vascular Plants. Springer-Verlag, Berlin, Heidelberg, New York.

Prance, G. T. 1976. The pollination and androphore structure of some Amazonian Lecythidaceae. Biotropica 8: 235-241.

RadamBrasil. 1983. Levantamento de recursos naturais, v. 32. folha $\mathrm{S}$ / F 23 / 24. Rio de Janeiro/ Vitória. Ministério das Minas e Energia, Rio de Janeiro.

Rizzini, C. T. 1979. Tratado de fitogeografia do Brasil. V.2. Aspectos Ecológicos. São Paulo.Hucitec / Edusp,.

Roubik, D. W.; D. Yanega; M. Aluja; S. S. L. Buchmann \& D. W. Inouye. 1995. On optimal nectar foraging by some tropical bees (Hymenoptera: Apidae). Apidologie 26: 197-211.

Silva, G. C. \& M. T. Nascimento. 2001. Fitossociologia de um remanescente de mata sobre tabuleiros no norte do estado do Rio de Janeiro (Mata do Carvão), RJ, Brasil. Revista Brasileira de Botânica 24: 51-62.

Villela, D. M.; M. T. Nascimento; L. E. O. C. Aragão \& D. M. Gama. 2006. Effect of selective logging on forest structure and nutrient cycling in a seasonally dry Brazilian Atlantic Forest. Journal of Biogeography 33: 506-516.

Vogel, S. 1990. The role of scent glands in pollination: On the structure and function of osmophores. Rotterdam. A. A. Balkema. 202 p.

Recebido em 17/07/2007; aceito em 10/03/2008 